\title{
Synthetic potential of heteroatomic ring systems*
}

\author{
Binne Zwanenburg \\ Department of Organic Chemistry, NSR Institute for Molecular Structure, Design and \\ Synthesis, University of Nijmegen, Toernooiveld, 6525 ED Nijmegen, Netherlands
}

\begin{abstract}
The synthesis of aziridine-2-carboxylic acid derivatives of high enantiopurity is described and their synthetic utility is discussed. Ring-opening and ring-expansion reactions of both oxirane and aziridine carboxylic esters are highlighted. Convenient syntheses of $\alpha$ hydroxy, $\beta$-amino and $\alpha$-amino, $\beta$-hydroxy carboxylic acids with defined stereochemistry are presented. The preparation of pyrrolidinone and azetidinone derivatives from functionalized three-membered heterocycles is described. Small-ring heterocycles also serve as the basis for the synthesis of catalysts, e.g. for an asymmetric reduction and for cyclopropanation reactions.
\end{abstract}

Functionalized small-ring heterocycles are highly attractive compounds from the synthetic point of view [1]. Aziridine-2-carboxylic esters, for instance, are of interest as they are structurally related to $\alpha$-as well as $\beta$-amino acids [2], and ring-opening reactions of oxiranecarboxylic acid derivatives allow the preparation of sterically defined $\alpha, \beta$-functionalized carboxylic acids. The strain present in these threemembered ring compounds ensures high reactivity in ring-opening and ring-expansion reactions [2]. We have developed a general and convenient synthesis of aziridine-2-carboxylic esters $\mathbf{1}$ from the corresponding oxiranecarboxylates $\mathbf{2}$ by successive treatment with sodium azide and triphenylphosphine [3]. The required starting materials in turn were prepared by Sharpless epoxidation of appropriate allylic alcohols [4], followed by oxidation of the 2,3-epoxy alcohols to the corresponding carboxylic acids using either ruthenium tetroxide or a two-step process involving a Swern oxidation and subsequent oxidation with sodium chlorite [3]. The sequence for the conversion of epoxy esters $\mathbf{2}$ into the aziridine esters $\mathbf{1}$ is depicted in Scheme 1.

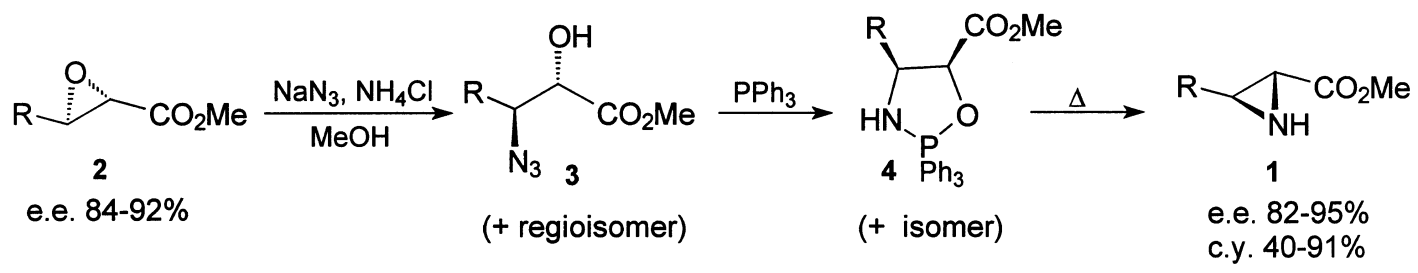

\section{Scheme 1}

The treatment with sodium azide results in an $\mathrm{S}_{\mathrm{N}} 2$-ring opening to give, in most cases, a mixture of regioisomeric azido alcohols 3 . Without separation this mixture is treated with triphenylphosphine to give the aziridine esters 1 via the intermediacy of oxazaphospholidines 4 [5]. This formation of the threemembered ring by the Staudinger reaction proceeds with inversion at the oxygen-bearing carbon atom. Thus, in the overall process from $\mathbf{2}$ to $\mathbf{1}$ an inversion at the $\alpha$ as well as the $\beta$ carbon atom takes place, with an excellent retention of chiral integrity. The procedure outlined in Scheme 1 has been utilized successfully for the synthesis of $(+)-(2 \mathrm{~S}, 3 \mathrm{~S})$-aziridine-2,3-dicarboxylic acid, a natural product isolated

\footnotetext{
*Lecture presented at the 5th International Conference on Heteroatom Chemistry (ICHAC-5), London, Ontario, Canada, 5-10 July 1998, pp. 369-512.

Correspondence: E-mail: zwanenb@sci.kun.nl
} 
from Streptomyces MD 398-A1 [6]. It is relevant to note that aziridinecarboxylic acids show the expected behavior for $\alpha$-amino acids in reaction with triethylboron, viz. the formation of boroxazolidines 5 [7]. Regiocontrolled ring-opening reactions of aziridine esters were accomplished with, for instance, thiophenol and indole as the nucleophiles, to give the anomalous amino acid derivatives 6 and 7 , respectively, [8] (Scheme 2).

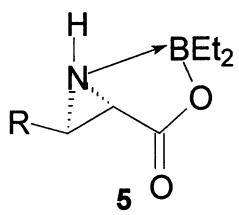<smiles>CC(=O)[C@H](N)C(c1ccccc1)c1ccccc1</smiles>

c.y. $67 \%$, e.e. $97 \%$<smiles>CC(=O)C(N)C(c1ccccc1)c1c[nH]c2ccccc12</smiles>

c.y. $64 \%$, e.e. $95 \%$

\section{Scheme 2}

A synthetically important reaction of aziridine as well as oxirane esters involves the ring expansion with acetonitrile in the presence of the mild Lewis acid catalyst boron trifluoride etherate. Alkyl substituted aziridine esters give imidazolines $\mathbf{8}$, which have a cis relationship between the alkyl substituent and the ester function implying that this reaction proceeds via initial nucleophilic attack of the nitrile in a $\mathrm{S}_{\mathrm{N}} 2$ fashion at the C-3 carbon atom (Scheme 3).

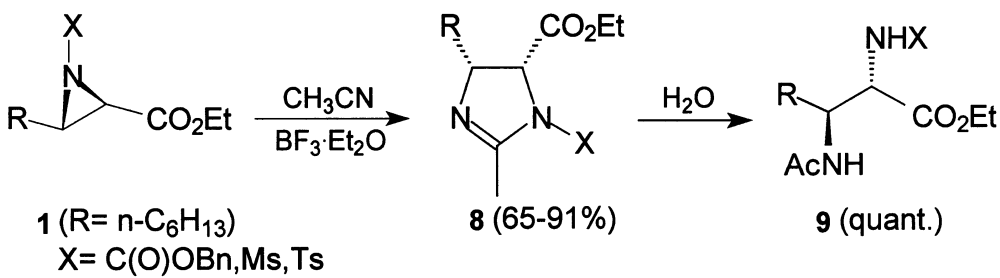

\section{Scheme 3}

Hydrolysis of the imidazolines 8 leads smoothly to $\alpha, \beta$-diamino-carboxylic acid derivatives 9 [9]. Similarly, the oxirane esters 2 react with acetonitrile in this modified Ritter reaction to produce oxazolines $\mathbf{1 0}$, which on hydrolysis give $\alpha$-hydroxy- $\beta$-amino-carboxylic acid derivatives $\mathbf{1 1}$ in high yield (Scheme 4) [10].
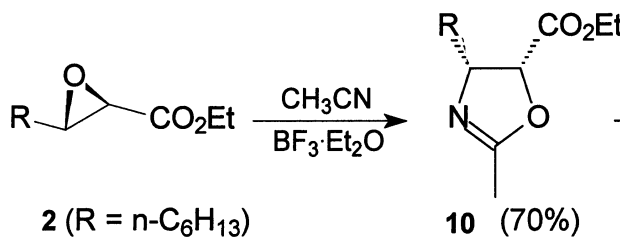

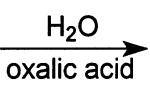

$10(70 \%)$<smiles>[R]C(NC)[C@H](O)C(=O)OCC</smiles>

$11(90 \%)$

\section{Scheme 4}

This sequence to the biologically highly relevant $\alpha$-hydroxy- $\beta$-amino-carboxylic acids was elaborated to a general synthetic protocol [11]. For this purpose, all four diastereomers of the starting oxiranecarboxylic esters 2 are required. They can be obtained either from $E$ and $Z$ allylic alcohols using the Sharpless epoxidation with the appropriate tartaric ester as the chiral auxiliary, or from $\alpha, \beta-$ unsaturated esters by asymmetric dihydroxylation employing the Sharpless procedure [12]. This general protocol was successfully utilized for the synthesis of several $\alpha$-hydroxy- $\beta$-amino-carboxylic acids such as the constituent of microgenin $\left(\mathrm{R}=n-\mathrm{C}_{7} \mathrm{H}_{15}\right)$, norstatin $\left(\mathrm{R}=i-\mathrm{C}_{4} \mathrm{H}_{9}\right)$, allo-phenylnorstatin $\left(\mathrm{R}=\mathrm{C}_{6} \mathrm{H}_{5} \mathrm{CH}_{2}\right)$ and iso-serine and iso-threonine [11].

For the synthesis of the isomeric $\alpha$-amino- $\beta$-hydroxy-carboxylic acids $\mathbf{1 4}$ the isomeric oxazolines 13 are needed. These compounds can elegantly be obtained from $N$-acyl-aziridine-2-carboxylic esters $\mathbf{1 2}$ by 
making use of the Heine ring-expansion reaction [13]. This nucleophile-assisted reaction proceeds with a double inversion, thus net retention, at C-3 (Scheme 5).

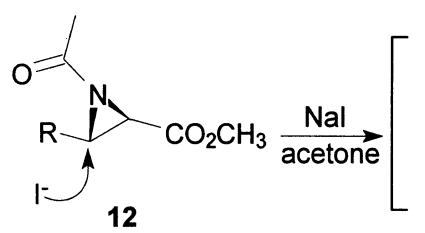

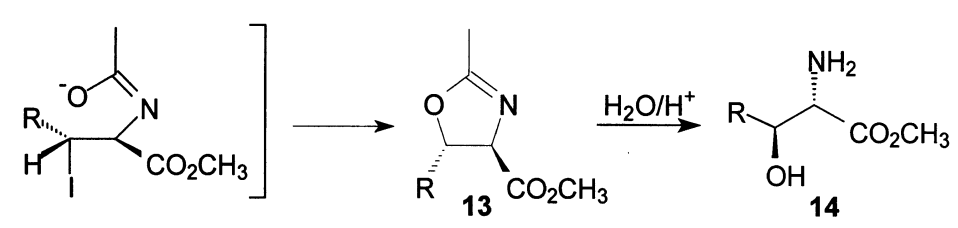

\section{Scheme 5}

Subsequent hydrolysis then produces the isomeric hydroxy amino acids $\mathbf{1 4}$. Combination of the abovementioned regiochemically complimentary synthesis of hydroxy amino acids with the convenient conversion of oxiranecarboxylic esters into the corresponding aziridine esters as outlined in Scheme 1, leads to the useful synthetic strategy for these amino acids as shown in Scheme 6. By choosing the right starting material the desired stereochemistry can be installed at the respective stereogenic centers [13].

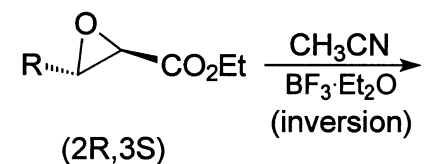

$(2 \mathrm{R}, 3 \mathrm{~S})$<smiles>[R]C1N=C(C)OC1C(=O)OC</smiles>

$(4 R, 5 R)$<smiles>[R]C(N)C([O])C(=O)OCC</smiles>

(2R,3R) $\alpha-\mathrm{OH}, \beta-\mathrm{NH}_{2}$

1. $\mathrm{NaN}_{3}$

2. $\mathrm{Ph}_{3} \mathrm{P}$

(inversion at both

C-2 and C-3)

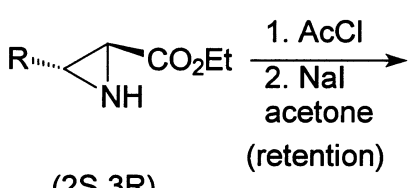<smiles>[R]C1OC(C)=NC1C(=O)O</smiles>

$(4 S, 5 R)$<smiles>C1CCCC1</smiles><smiles>[R]C(O)C(N)C(=O)OCC</smiles>

(2S,3R)

$\alpha-\mathrm{NH} 2, \beta-\mathrm{OH}$

\section{Scheme 6}

An alternative mode for the synthetic elaboration of the three-membered heterocycles $\mathbf{1}$ and $\mathbf{2}$ proceeds by a modification of the ester function. An example is formation of an amide 15a derived from aminomalonic ester is depicted in Scheme 7.

$\stackrel{\text { Rin.... }}{\text { 1. TsCl, Et } \mathrm{Et}_{3} \mathrm{~N}, \mathrm{DMAP}, \mathrm{CH}_{2} \mathrm{Cl}_{2}}$

$1\left(\mathrm{R}=\mathrm{n}-\mathrm{C}_{6} \mathrm{H}_{13}\right)$<smiles>[R]C1CC1C(=O)NC(C(=O)OCC)C(=O)OCC</smiles><smiles>[R]C1[C@H](NC)C(=O)N[C@@]1(OCC)C(=O)OCC</smiles>

\section{Scheme 7}

These compounds undergo an intramolecular ring expansion to pyrrolidinone $\mathbf{1 6}$ when treated with a catalytic amount of sodium ethoxide in ethanol [14]. The stereochemical course of this reaction, namely an internal $\mathrm{S}_{\mathrm{N}} 2$ reaction, was unambiguously established by an X-ray analysis of the product 16a [14]. Remarkably, the $N$-t-butyloxycarbonyl-aziridine derivative $\mathbf{1 5 b}$ showed a deviant behaviour when treated 
with two equivalents of lithio diisopropylamide in tetrahydrofuran. Under these kinetically controlled conditions an exclusive reaction takes place with the $N$-t-butyloxycarbonyl group to give bicyclic aziridine product 17 (Scheme 8) [14].<smiles>[R]C1[C@H](NC(=O)OCc2ccco2)C(=O)NC1(C(=O)OCC)C(=O)OCC</smiles>

16b

$(78 \%)$<smiles>[R]C1C(C(=O)NC(C(=O)OCC)C(=O)OCC)C1C(=O)OCCN</smiles>

\section{Scheme 8}

Under thermodynamically controlled conditions, i.e. treatment with sodium ethoxide, the malonyl proton is abstracted followed by an intramolecular reaction of the malonate carbanion to give $\mathbf{1 6} \mathbf{b}$, whereas with lithio diisopropylamide deprotonation of the amide hydrogen takes place with subsequent reaction of the thus-formed anion with the hard carbonyl carbon instead of the softer aziridine-ring carbon [14]. It is of interest to note that the corresponding cis aziridine derivative of 15a failed to react under any basic condition, probably due to unfavorable steric interactions during the intramolecular attack. The corresponding oxiranecarboxamide derivative can be prepared by a similar coupling reaction with aminomalonate. Subsequent treatment with sodium ethoxide in ethanol leads to the formation of the corresponding hydroxy substituted pyrrolidinone in good yield [14]. The original objective of these intramolecular ring expansion experiments was to prepare $\beta$-lactam derivatives (Scheme 9).

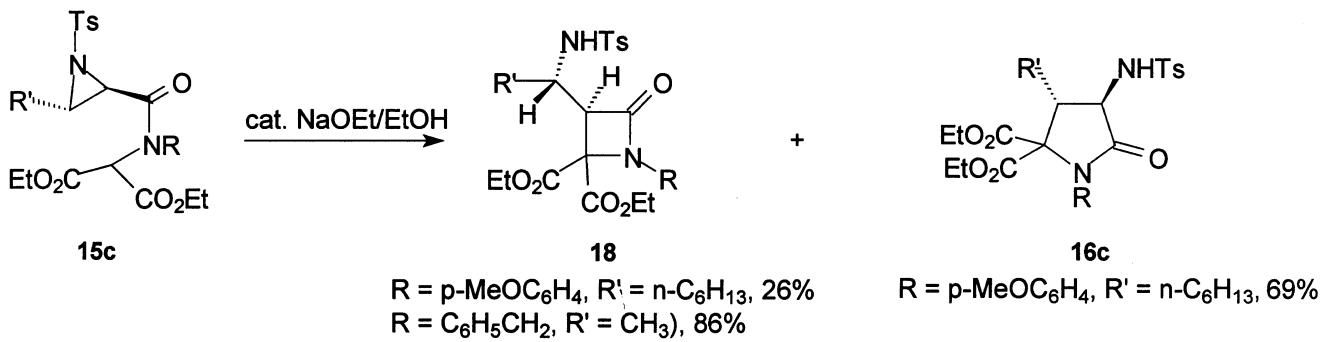

\section{Scheme 9}

This reaction could only be accomplished for aziridinecarboxamides in which the amide $\mathrm{N}-\mathrm{H}$ is replaced by an anisyl or benzyl group. In the latter case, the yield of $\beta$-lactam was high, however, in the former case a considerable amount of five-membered product $\mathbf{1 6} \mathbf{c}$ was also produced $[13,14]$.

Another fruitful application of the heterocyclic esters $\mathbf{1}$ and $\mathbf{2}$ involves the Knoevenagel reaction of the aldehyde 19 obtained by reduction of the ester function (Scheme 10) [15].

The compounds $\mathbf{2 0}$ obtained in this manner undergo a Michael Initiated Ring Closure (MIRC) reaction upon treatment with suitable nucleophiles to give functionalized cyclopropanes $\mathbf{2 1}$. The best results were obtained with alkylmagnesium halides in the presence of $10 \mathrm{~mol} \%$ of copper(I) cyanide (Scheme 10) [15]. A similar MIRC reaction was performed with oxiranyl derivatives [17]. It was shown that the corresponding cis-aziridinyl-methylene malonates produce predominantly the trans cyclopropane product. The stereochemical course of this MIRC reaction was explained [15] by invoking Yamamoto's model for conjugate additions of cyanocuprates to $\gamma$-alkoxy- $\alpha, \beta$-unsaturated esters [16].

A convenient synthesis of methyl and unsubstituted aziridine-2-carboxylic esters makes use of the readily available amino acids serine (22a) and threonine (22b), respectively, as the starting material (Scheme 11) [18].

The tritylated amino acids $\mathbf{2 3}$ are treated with two equivalents of methanesulfonyl chloride in the presence of triethylamine to produce $\mathbf{2 4}$ in good yields. This method of preparation has attracted 


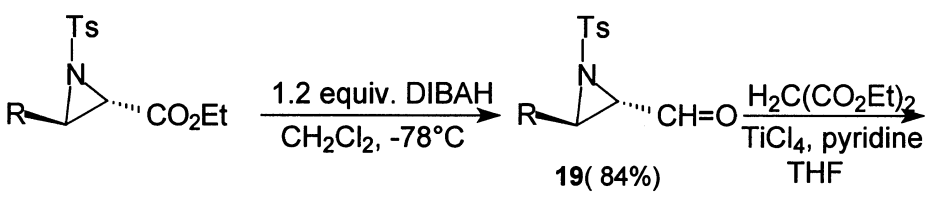

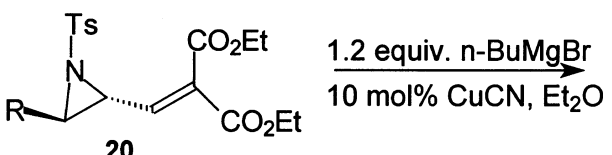

20

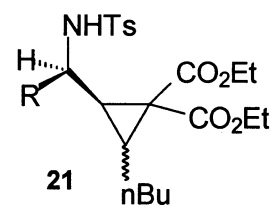

cis : trans $=85: 15$

Scheme 10<smiles>[R]C(O)[C@H](N)C(C)=O</smiles>

22 a $(R=H), b(R=M e)$

23

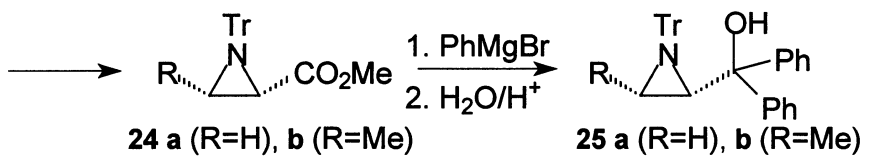

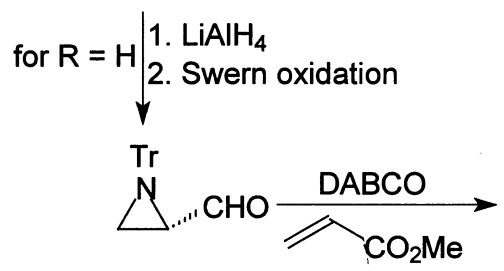

$2780 \%$<smiles>[CH]N1C[C@@H]1[C@H](O)C(=C)C(C)=O</smiles>

$28(82 \%)$

syn/anti $=1: 1$

Scheme 11

considerable attention in the literature [19]. Our improved experimental procedure [18] is applicable on multigram scale. The thus-prepared $N$-trityl-aziridine ester $\mathbf{2 4}$ can be readily converted into the carbinols $\mathbf{2 5}$, which serve as the basis for the in situ formation of oxazaborolidines $\mathbf{2 6}$ during the asymmetric reduction of ketones with borane (Scheme 12) [20].

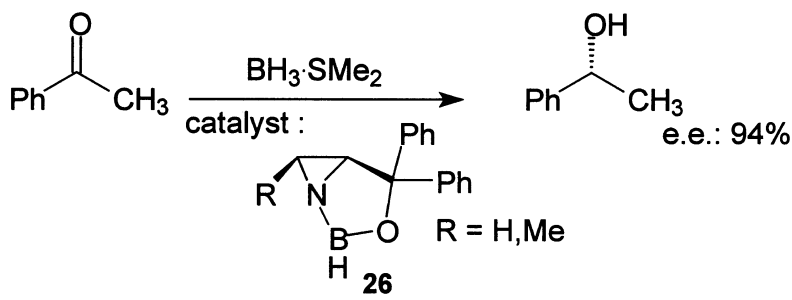

Scheme 12 
High enantioselectivities were obtained for the reduction of acetophenone, comparable with those obtained with Corey's $\alpha, \alpha$-diphenyl-2-pyrrolidinemethanol as the precatalyst [21].

The tritylated aziridine carboxaldehyde 27 turned out to be a very interesting compound. It underwent a surprisingly facile Baylis-Hillman reaction with a variety of activated vinyl compounds, e.g. methyl acrylate, in the presence of DABCO (Scheme 11) [22]. The synthetic utility of the Baylis-Hillman adducts is currently under active investigation.

So far, the focus was on the synthetic potential of functionalized three-membered ring heterocycles. The four-membered ring counterparts however, are of equal interest. Remarkably, the chemistry of azetidine-2-carboxylic acids and derivatives has received relatively little attention in the literature. We have developed a convenient synthesis of enantiopure $N$-alkyl-azetidine-2-carboxylic esters using an enzymatic resolution [23], which is detailed in Scheme 13.<smiles>O=C1CCCO1</smiles><smiles>[Y][R18]([Y])(Br)C[Pb]</smiles><smiles>CC(=O)C(Br)CCBr</smiles>

27

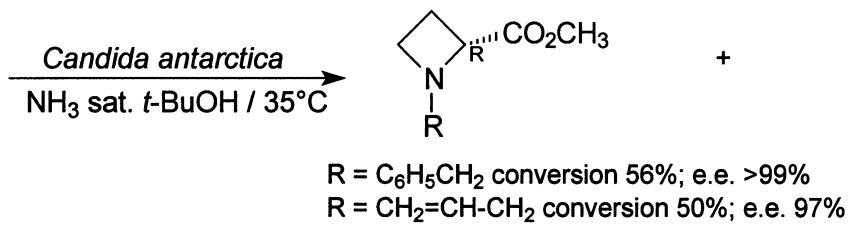<smiles>[R]N1CCC1C(C)=O</smiles><smiles>[R]N1CC[C@H]1C(N)=O</smiles>

e.e. $>99 \%$

e.e. $97 \%$

\section{Scheme 13}

Attempts to accomplish an enzymatic enantioselective hydrolysis of azetidine esters $\mathbf{2 8}$ (rac) were unsuccessful. Gratifyingly, lipase-mediated ammoniolysis could be realized with a remarkably high enantioselectivity [23]. It is worth noting that thus far there was no satisfactory route available for the preparation of the unnatural enantiomer of azetidine-2-carboxylic acid or a derivative thereof. An alternative approach to enantiopure azetidine-2-carboxylic acid derivatives is shown in Scheme 14.<smiles>CC(=O)CCC(C)N</smiles><smiles>[R19]N1CCC1C(O)(c1ccccc1)c1ccccc1</smiles><smiles>CC(=O)C1CCN1C(C)c1ccccc1</smiles>

29a<smiles>CC(=O)[C@H]1CCN1C(C)c1ccccc1</smiles>

$29 b$

\section{Scheme 14}

Here dibromide $\mathbf{2 7}$ is treated with (S)- $\alpha$-methylbenzylamine to a readily separable diastereomeric mixture of $\mathrm{N}$-alkylazetidines 29 [24]. A similar approach was followed for an azetidine-2,4-dicarboxylate [25]. These azetidine esters $\mathbf{2 8}$ and $\mathbf{2 9}$ were used to prepare the carbinol $\mathbf{3 0}$, which served as chiral auxiliary in the $\mathrm{BBr}_{3}$ catalyzed Diels-Alder reaction of cyclopentadiene and acrolein-type dienophiles. It was found that the stereoselectivities are highly dependent on the dienophile/chiral auxiliary combination [24].

Aziridine and azetidine carboxylic acids were utilized for the preparation of chiral dirhodium catalysts for asymmetric cyclopropanation reactions (Scheme 15) [26].

The diastereoselectivity as expressed by the $E / Z$ ratio of the cyclopropanes obtained, is much higher for styrene than for $\alpha$-methylstyrene. The rhodium catalysts derived from the three-and four-membered 


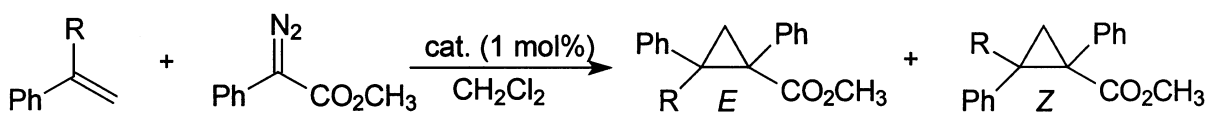

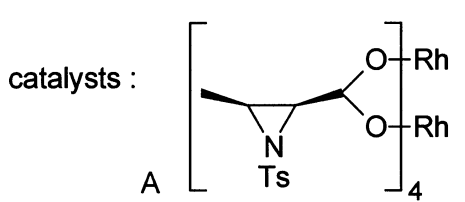

for $\mathrm{R}=\mathrm{H}$

for $\mathrm{R}=\mathrm{CH}_{3}$
$A: E / Z=99 / 1$ e.e. $(E): 31 \%$

$A: E / Z=2.9 / 1$ e.e. $(E): 26 \%$<smiles>O=C(c1ccccc1)N1CCC1C(Oc1ccccc1)OS(=O)(=O)OCc1ccccc1</smiles>

B: $E / Z=98 / 2$ e.e. $(E): 35 \%$

B: $E / Z=2.7 / 1$ e.e. $(E): 43 \%$

\section{Scheme 15}

ligands show better diastereocontrol in both reactions than observed for the cyclopropanations using the corresponding proline derived catalyst but the latter shows better enantiocontrol [26]. Davis et al. [27] also studied catalyst B (Scheme 15) in related cyclopropanation reactions. These authors also reported extensively on the use of the rhodium prolinate catalyst $[27,28]$.

In this brief overview it is clearly demonstrated that functionalized small-ring heterocycles have a rich synthetic utility. They can be utilized for the preparation of compounds of potential biological interest as well as for interesting new ligands for catalytic systems.

\section{ACKNOWLEDGEMENTS}

The author thanks his skilful co-workers for their valuable contributions.

\section{REFERENCES}

1 J. A. Deyrup. In Small Ring Heterocycles, Part 1 (A. Hassner, ed.), pp. 11. Wiley Interscience, New York (1983).

2 D. Tanner. Angew. Chem. Int. Ed. Engl. 33, 599 (1994); D. Tanner. Pure Appl. Chem. 65, 1319 (1993); H. M. I. Osborn, J. Sweeney. Tetrahedron: Asymmetry 8, 1693 (1997); B. Zwanenburg, L. Thijs. Pure Appl. Chem. 68, 735-738 (1996).

3 J. Legters, L. Thijs, B. Zwanenburg. Tetrahedron Lett. 30, 4881 (1989); J. Legters, L. Thijs, B. Zwanenburg. Recl. Trav. Chim. Pays-Bas 111, 1 (1992).

4 Y. Gao, R. M. Hanson, J. M. Klunder, S. Y. Ko, H. Masamune, K. B. Sharpless. J. Am. Chem. Soc. 109, 5765 (1987).

5 J. J. M. Smits, P. T. Beurskens, L. Thijs, A. A. W. M. van, Loon, B. Zwanenburg. J. Cryst. Spectr. Res. 18, 625 (1988).

6 J. Legters, L. Thijs, B. Zwanenburg. Tetrahedron Lett. 28, 5287 (1991).

7 J. Legters, L. Thijs, B. Zwanenburg. Recl. Trav. Chim. Pays-Bas 111, 211 (1992).

8 J. Legters, L. Thijs, B. Zwanenburg. Recl. Trav. Chim. Pays-Bas 111, 16 (1992).

9 J. Legters, J. G. H. Willems, L. Thijs, B. Zwanenburg. Recl. Trav. Chim. Pays-Bas 111, 59 (1992).

10 J. Legters, E. van, Dienst, L. Thijs, B. Zwanenburg. Recl. Trav. Chim. Pays-Bas 111, 69 (1992).

11 L. Thijs, C. Afraz, B. Zwanenburg, to be published.

12 E. N. Jacobsen, I. Markó, W. S. Mungall, G. Schröder, K. B. Sharpless. J. Am. Chem. Soc. 110, 1968 (1988); H. C. Kolb, M. S. Van Nieuwenhze, K. B. Sharpless. Chem. Rev. 94, 2483 (1994).

13 Unpublished results from the author's laboratory.

14 I. Funaki, L. Thijs, B. Zwanenburg. Tetrahedron 52, 9909 (1996).

15 I. Funaki, R. P. L. Bell, L. Thijs, B. Zwanenburg. Tetrahedron 52, 12253 (1996).

16 Y. Yamamoto, Y. Chounan, S. Nishii, T. Ibuka, H. Kitahara. J. Am. Chem. Soc. 114, 7652 (1992).

17 A. N. Kasatkin, A. N. Kulak, R. Kh. Biktimirov, G. A. Tolstikov. Tetrahedron Lett. 31,4915 (1990). 
18 J. G. H. Willems, M. C. Hersmis, R. de Gelder, J. M. M. Smits, J. B. Hammink, F. J. Dommerholt, L. Thijs, B. Zwanenburg. J. Chem. Soc. Perkin Trans 1, 963 (1997).

19 Y. Nakagawa, T. Tsuno, K. Nakajima, M. Iwai, H. Kawai. Bull. Chem. Soc. Jpn 45, 1162 (1972); K. Nakajima, F. Takai, T. Tanaka, K. Okawa. Bull. Chem. Soc. Jpn 51, 1577 (1978); T. Wakamiya, K. Shimbo, T. Shiba, K. Nakajima, M. Neya, K. Okawa. Bull. Chem. Soc. Jpn 55, 3878 (1982); E. Kuyl-Yeheskiely, M. Lodder, G. A. van der Marel, J. H. van Boom. Tetrahedron Lett. 33, 3013 (1992).

20 J. G. H. Willems, F. J. Dommerholt, J. B. Hammink, A. M. Vaarhorst, L. Thijs, B. Zwanenburg. Tetrahedron Lett. 36, 603 (1995).

21 E. J. Corey, R. K. Bakshi, S. Shibata. J. Am. Chem. Soc. 109, 5551 (1987).

22 S. K. Nayak, L. Thijs, B. Zwanenburg. Tetrahedron Lett. 40, 981 (1999).

23 W. A. J. Starmans, R. G. Doppen, L. Thijs, B. Zwanenburg. Tetrahedron: Asymmetry 9, 429 (1998).

24 W. A. J. Starmans, R. W. A. Walgers, L. Thijs, R. de, Gelder, J. M. M. Smits, B. Zwanenburg. Tetrahedron 54, 4991 (1998).

25 J. Hoshino, J. Hiraoka, Y. Hata, S. Sawada, Y. Yamamoto. J. Chem. Soc. Perkin Trans 1, 693 (1995).

26 W. A. J. Starmans, L. Thijs, B. Zwanenburg. Tetrahedron 54, 629 (1998).

27 H. M. L. Davies, P. R. Bruzinsky, D. H. Lake, N. Kong, M. J. Fall. J Am. Chem. Soc. 118, 6897 (1996).

28 H. M. L. Davies, Z.-Q. Peng, J. H. Houser. Tetrahedron Lett. 35, 8939 (1994); H. M. L. Davies, P. R. Bruzinski, M. J. Fall. Tetrahedron Lett. 37, 4133 (1996); H. M. L. Davies, N. Kong. Tetrahedron Lett. 38, 4203 (1997); H. M. L. Davies. Aldrichimica Acta 30, 107 (1997), and references cited therein. 